\title{
Rancang bangun alat uji pompa sentrifugal bahan bakar solar sebagai media pembelajaran dan praktikum mahasiswa Program Studi Teknik Mesin Universitas Muhammadiyah Pontianak skala laboratorium
}

\author{
Gunarto $^{1^{*}}$, Suje' $^{2}{ }^{2}$, Doddy Irawan ${ }^{3}$, Eko Julianto $^{4}$ \\ ${ }^{1,2,3,4}$ Program Studi Teknik Mesin, Fakultas Teknik dan IImu Komputer, Universitas \\ Muhammadiyah Pontianak \\ Jl. A.Yani No.111 Pontianak, Kalimantan Barat, Indonesia \\ ${ }^{*}$ Corresponding authors: guncici75@gmail.com
}

\begin{abstract}
This study aims to produce a diesel oil transfer device using a pump as a learning medium as well as a practical pump course for students of the Mechanical Engineering Study Program, University of Muhammadiyah Pontianak. This design needs to be made as an effort to stimulate learning motivation, improve students' understanding and thinking skills in pumping courses. The research stages are carried out by designing the design and manufacture or assembling of the diesel oil transfer device into a unified whole, as well as testing the tool so that it can be used for learning media and practicum. Data collection and retrieval is adjusted to the test instrument instrument. The result of this research is a learning and practical media tool to test the characteristics of diesel oil centrifugal pumps. This oil transfer device can operate properly and has met the standards of the pump used. This media can be used as a lecturer to facilitate the learning process for pump courses. In addition, this tool is worthy of being used as a practicum tool for centrifugal pump performance specifically for diesel oil pumps.
\end{abstract}

Keywords: design, oil transfer tools, learning media, practicum

Abstrak

Penelitian ini bertujuan untuk menghasilkan alat transfer minyak solar dengan menggunakan pompa sebagai media pembelajaran serta praktikum mata kuliah pompa bagi mahasiswa Program Studi Teknik Mesin Universitas Muhammadiyah Pontianak. Rancang bangun ini perlu dibuat sebagai upaya untuk memacu motivasi belajar, meningkatkan pemahaman dan kemampuan berpikir mahasiswa terhadap mata kuliah pompa. Tahapan penelitian dilakukan dengan perancangan design dan pembuatan atau perakitan alat transfer minyak solar menjadi satu kesatuan yang utuh, serta pengujian alat sehingga bisa digunakan untuk media pembelajaran serta praktikum. Pengumpulan dan pengambilan data disesuaikan dengan instrument alat uji. Hasil penelitian ini adalah sebuah alat media pemebelajaran dan praktikum untuk uji karakteristik dari pompa sentrifugal minyak solar. Alat transfer minyak ini dapat beroperasi dengan baik dan sudah memenuhi standar dari pompa yang dipergunakan. Media ini dapat dijadikan dosen untuk mempermudah proses pembelajaran mata kuliah pompa. Selain itu, alat ini sudah layak dijadikan alat praktikum unjuk kerja pompa sentrifugal khusus pompa minyak solar.

Kata kunci: rancang bangun, alat transfer minyak , media pembelajaran, praktikum

\section{Pendahuluan}

Dalam mengajar mahasiswa sebagai sumber daya negara, penting untuk mengembangkan berbagai sarana dan prasarana untuk membantu dalam memahamai ilmu pengetahuan. 
Membiasakan ilmu-ilmu rancang bangun yang telah berjalan, khususnya pembelajaran di bidang mesin konversi energy yaitu mata kuliah Pompa di Program Studi Teknik Mesin Fakultas Teknik dan Ilmu Komputer Universitas Muhammadiyah Pontianak, masih dirasa penting untuk dikembangkan lebih lanjut. agar terjadi interaksi belajar secara ideal. Permasalahan tersebut tampak meskipun tidak adanya sarana dan sarana peralatan yang memadai untuk membantu praktikum, khususnya di bidang pompa, dari hasil pengamatan proses pembelajaran ternyata kemauan mahasiswa dalam belajar jauh berkurang dan kemampuan siswa untuk memahami materi kuliah pompa masih sangat rendah karena kesulitan dalam mempelajari materi, buku mata kuliah, dan modul pompa. Dalam pembelajaran, terlihat jelas bahwa mahasiswa kurang semangat, kemampuan rendah, jarang bertanya dan tidak berusaha untuk mengkomunikasikan pemikirannya tentang materi yang diberikan. Mahasiswa kurang dinamis dalam mempelajari mata kuliah pompa.

Mahasiswa jarang mengajukan pertanyaan atau mengungkapkan pikiran mereka meskipun faktanya bahwa dosen berulang kali mengajukan pertanyaan. Selain itu, mahasiswa untuk membaca buku referensi juga masih rendah.

Akibat rumitnya mata kuliah pompa, tidak cukup hanya ditampilkan secara teori maupun hipotetis di kelas, namun penting untuk memiliki media atau perangkat pembelajaran lain guna membangun pemahaman materi kuliah pompa ini. Oleh sebab itu, sangat penting untuk mendesain perangkat pembelajaran melalui perencanaan perangkat alat transfer minyak bahan bakar solar skala laboratorium dengan menggunakan pompa minyak sebagai media belajar dan prkatikum yang dapat dijadikan pilihan belajar mahasiswa selain teori di kelas. Tujuan akhir dari perancangan media pembelajaran ini untuk membangun pemahaman siswa terhadap mata kuliah pompa.

Kelangsungan program instruktif dapat dilihat dari:

1. Pencapaian program sesuai dengan tujuan informatif yang diharapkan.

2. Kontribusi siswa yang dinamis untuk mempermudah pencapaian tujuan informatif.

3. Peralatan dan sarana pendukung yang memadai dalam interaksi pembelajaran [1].

Penggunaan dan pemanfaatan media dalam siklus pembelajaran adalah untuk pembelajaran yang efektif dan membuat lebih efisien pendidikan dan pembelajaran itu sendiri [2].

Media pembelajaran berperan dalam memberikan, membuat mahasiswa agar lebih mudah memahami dan menyebarkan data atau informasi dan latihan-latihan dalam pembelajaran di suatu lembaga atau landasan instruktif sehingga mereka dapat memperoleh data atau informasi tersebut [3].

Tujuan rancangan instrumen ini selain digunakan sebagai media pembelajaran untuk memperluas inspirasi, kapasitas, kemampuan dan pemahaman mahasiswa terhadap materi pompa, juga dapat dimanfaatkan sebagai perangkat praktikum yang layak.

Dengan praktikum siswa akan mendapatkan pengalaman belajar, dan akan mengenal lebih jauh tentang pemanfaatan pompa yang digunakan dan langsung mengetahui efek samping yang terjadi pada pengujian perangkat tersebut. Melalui pelatihan di pusat penelitian ini, mahasiswa akan semakin memahami materi pompa dengan melakukan latihan yang sungguhsungguh.

Dalam penelitian ini, penulis membuat perangkat pembelajaran pompa minyak solar sebagai media dan alat praktikum pengujian pompa sederhana. Untuk tujuan fungsional, instrumen ini dapat digunakan untuk menentukan atau mencari kinerja pompa, minor dan mayor losses, pressure drop. 


\section{Tinjauan Pustaka}

Pompa merupakan alat yang dipergunakan untuk menstransfer fluida cair dari suatu tempat ke tempat yang lain melalui sistem peepipaan (piping sistem). Biasanya sistem ini terdiri dari tangki suction dan discharge, sebuah pompa, dan sambungan pipa yang terdiri dari pipa, katup (valve), elbow dan tee. Energi yang di perlukan untuk memindahkan dari $1 \mathrm{lb}$ cairan, pada laju aliran (flow rate) yang diinginkan dari tangki suction ke tangki discharge disebut head sistem (sistem head). Pompa harus memasok energi ini. Dengan kata lain, head total yang dihasilkan oleh pompa harus sama dengan head total yang diperlukan oleh sistem [4].

Pompa sentrifugal adalah jenis pompa kerja dinamik yang digunakan untuk untuk menaikan fluida dari permukaan yang rendah ke lebih tinggi atau pompa dipergunakan untuk mendistribusikan air yang tekanannya rendah ke tinggi [5][6].

Penelitian dan pengujian terhadap minor losses dan mayor losses pada pompa dan instalasi perpipaan ini menarik sekali sehingga banyak dilakukan oleh beberapa peneliti dan balai pengujian untuk menguji dan beberapa penyebab dari aspek yang berbeda berdasarkan hasil pengujian yang telah dilakukan untuk variasi bukaan katup terhadap kapasitas air diperoleh bahwa pembukaan katup akan mempengaruhi debit yang dihasilkan [7] .

Penggunaan berbagai variasi sudut belokan menyebabkan terjadinya perubahan pada kerugian-kerugian (head losses) dan penururnan tekanan (pressure drop). Sehingga ketika sudut belokan makin besar, nilai head losses dan pressure drop juga semakin besar. Head losses dan pressure drop paling kecil terjadi pada sudut $30^{\circ}$ yaitu $73,23 \mathrm{~mm}$ dan 903,606 $\mathrm{N} / \mathrm{m}^{2}$, sedangkan head losses dan pressure drop paling besar terjadi pada sudut $90^{\circ}$ yaitu $74,80 \mathrm{~mm}$ dan $1278,899 \mathrm{~N} / \mathrm{m}^{2}$ [8]

Nilai koefisien kerugian-kerugian minor Elbow 90 dan Elbow 45, berbanding terbalik terhadap kecepatan rata-rata alirannya. Nilai koefisien minor losses terhadap Y-Junction dan T-Junction, Juga mengalami perbandingan terbalik dengan kecepatan aliran fluida, namun pada $\mathrm{T}$ Junction sedikit ada gejolak, namun cenderung turun dengan semakin besarnya kecepatan aliran yang terjadi [9].

Nilai kerugian pada percabangan mempengaruhi kenaikan debit. Ketika penampang aliran memeiliki luas yang kecil maka akan memberikan kerugian yang sangat tinggi. Sedangkan head total pompa akan sangat berpengaruh terhadap besarnya efisiensi pompa [10].

Dalam sistem perpipaan tidak lepas dari kerugian karena adanya berbagai macam kerugian gesek dan aksesoris di sistem perpipaan itu sendiri.Analisa kerugian pada sambungan konvergen dan divergen bertujuan untuk mengetahui kerugian yang terjadi pada aksesoris perpipaan oleh sambungan elbow,tee dan lain-lain. Hasil analisa diperoleh bahwa keugian sambungan konvergen lebih besar dari sambungan divergen [11].

\section{Metode Penelitian}

Dasar penelitian digunakan yang akan dilakukan sesuai dengan tujuan yang hedak dicapai yaitu alat yang dapat dipertanggung jawabkan secara ilmiah. Alat transfer minyak ini dibuat sesuai dengan landasan perencanaan yaitu berupa studi kepustakaan seperti pengumpulan bahan atau material yang dibutuhkan dalam rancang bangun alat transfer minyak bahan bakar solar skala laboratorium, dan material-material yang mendukung dan sesuai, serta pengumpulan literatur sebagai pegangan untuk menyelesaikan suatu permasalahan.

Adanya literatur ini, permasalahan yang terdapat dalam penelitian nanti bisa teratasi dengan pemahaman konsep yang ada. Di metode eksperimen ini, kontruksi alat yang telah direncanakan sebelumnya kemudian direalisasikan dalam sebuah alat, selanjutnya akan digunakan dalam percobaan (eksperimen).

Penelitian yang dilakukan ini 
menggunakan true experimental research dengan mendesain,membuat dan menguji alat.

Alat media pembelajaran dan praktikum alat transfer minyak menggunakan pompa ini dibuat di Laboratorium Teknik Mesin Universitas Muhammadiyah Pontianak, yang terletak di Ambawang Kubu Raya. Alat ini terdiri dari pipa PVC, 3 buah pompa sentrifugal, pressure gauge, flowmeter yang dirangkai menjadi satu kesatuan utuh, seperti yang ditunjukkan pada Gambar 1.

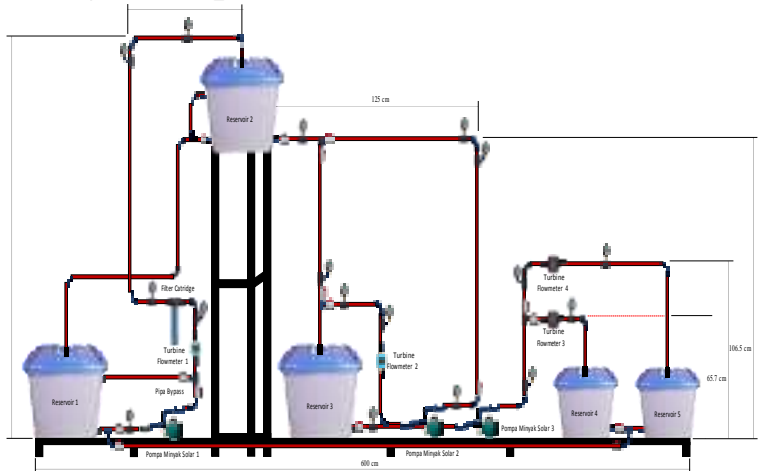

Gambar 1. Desain alat

Sistem jaringan perpipaan pada instalasi pompa cairan kental bahan bakar solar ini di rancang sebagai bentuk penelitian skala laboratorium guna melayani proses transfer minyak bahan bakar solar dari Reservoir 1 ke penyimpanan Reservoir 2 dengan menggunakam pompa cairan kental (pompa 1) yang melewati Turbine Flowmeter 1 dan Filter Catridge. Pada saat minyak bahan bakar solar tertampung pada Reservoir 2, maka akan di transfer kembali ke Reservoir 3 dengan menggunakan pompa cairan kental (pompa 2) dengan melewati Turbine Flowmeter 2 dan dengan sistem gravitasi, selanjutnya akan dipompakan oleh pompa cairan kental menuju masing - masing bak penampung berikutnya, yaitu Reservoir 4 dan Reservoir 5 dengan menggunakan pompa cairan kental (pompa 3) dengan melewati Turbine Flowmeter 3 dan Turbine Flowmeter 4.

Perancangan alat uji penelitian transfer minyak solar mencakup pekerjaan yang dilakukan mulai dari Reservoir 1 ke Reservoir 2 menggunakan pompa 1 dan dari Reservoir 2 minyak solar akan di transfer kembali ke Reservoir 3 menggunakan pompa 2 dan dengan sistem gravitasi. Selanjutnya minyak solar akan di transfer lagi ke Reservoir 4 dan Reservoir 5 dengan menggunakan pompa 3. Bahan bakar minyak solar di Reservoir 2 yang akan di transfer kembali ada dua sistem yaitu menggunakan sistem gravitasi dan sistem paksa (pompa 2). Dimana dalam sistem paksa ini pompa berfungsi guna mengatasi tekanan balik dari Reservoir 3 .

Dalam rancang bangun alat uji transfer minyak solar ini pipa yang dipergunakan untuk mengalirkan minyak solar dengan dengan sistem gravitasi adalah sama dengan pipa yang dipergunakan dengan pompa hanya berbeda jarak yang disesuaikan sistem jaringan perpipaan. Dalam sistem jaringan perpipaan transfer minyak solar ini dipergunakan Pompa Cairan Kental FIRMAN FDP-20 Pompa Solar dan Oli (Pompa Sentrifugal) di masing - masing sistem (pompa 1, pompa 2 \& pompa 3). Untuk panjang pipa yang terpasang dari Reservoir 1 ke Reservoir 2 panjangnya adalah $6,110 \mathrm{~m}$ dengan diameter pipa $3 / 4$ ". Untuk panjang pipa dari Reservoir 2 ke Reservoir 3 secara sistem gravitasi memiliki panjang adalah 3,055 m dengan diameter pipa $3 / 4$ ", sedangkan untuk panjang pipa dari Reservoir 2 ke Reservoir 3 dengan sistem paksa (pompa 2) panjangnya adalah $6,489 \mathrm{~m}$ dengan diameter pipa yang sama. Dari Reservoir 3 bahan bakar minyak solar akan di transfer lagi menggunakan sistem paksa (pompa 3) menuju ke Reservoir 4 dan Reservoir 5. Panjang Pipa dari Reservoir 3 ke Reservoir 4 adalah 2,951 m dan dari Reservoir $3 \mathrm{ke}$ Reservoir 5 panjang pipanya adalah 3,801 $\mathrm{m}$ dengan diameter pipa yang sama yaitu $3 / 4 "$

Untuk memperkirakan besarnya kebutuhan minyak bahan bakar solar pada sebuah proses transfer minyak solar, maka perhitungan kapasitas pompa ini didasarkan pada kapasitas pengoperasian pompa 1, pompa 2 dan pompa 3, akan menghasilkan kapasitas minimum sebesar 25 LPM dan 
kapasitas maksimum sebesar 53 LPM sesuai dengan spesifikasi dari pompa cairan kental FIRMAN FDP-20 Pompa Solar dan Oli.

Sehingga perhitungan kapasitas pompa cairan kental ini didasarkan pada kapasitas yang paling besar (maksimal) dari pengoperasian dimasing - masing pompa (pompa 1, pompa 2 dan pompa 3 ) tersebut yaitu sebesar 53 liter/menit.

\section{Hasil dan Pembahasan}

Hasil perancangan dan pembuatan model media pembelajaran ini didapatkan peralatan untuk praktikum pengujian karakteristik dan unjuk kerja pompa sentrifugal minyak solar di laboratorium Teknik Mesin Universitas Muhammadiyah Pontianak. Alat ini sudah dapat dipergunakan sebagai media pembelajaran dan praktikum. Dibawah ini adalah fotofoto proses perancangan.

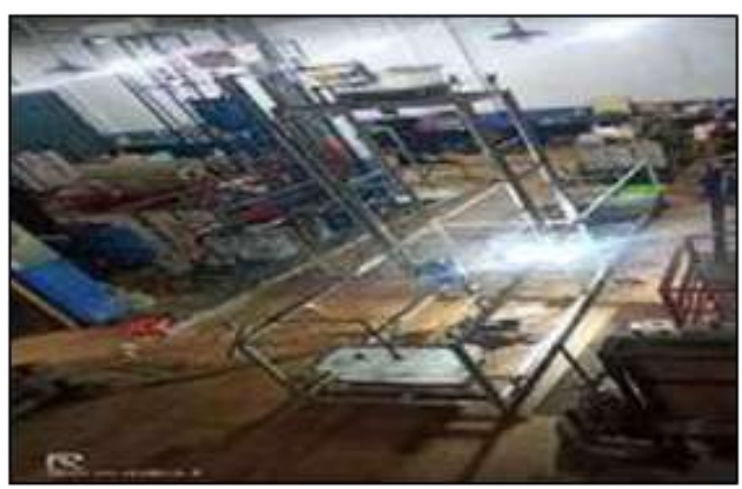

Gambar 2. Pembuatan kerangka

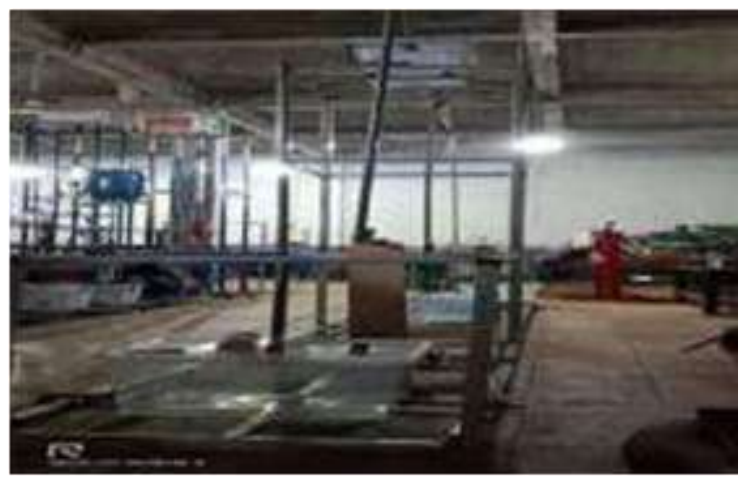

Gambar 3. Pemasangan Reservoir

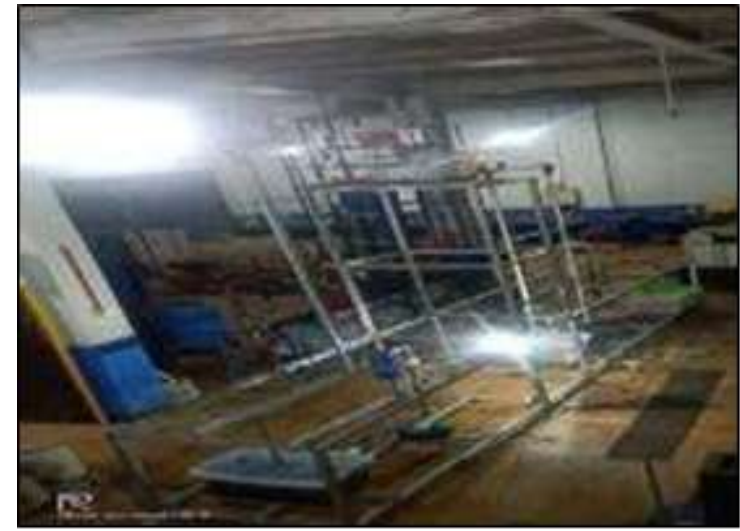

Gambar 4. Reservoir isi solar

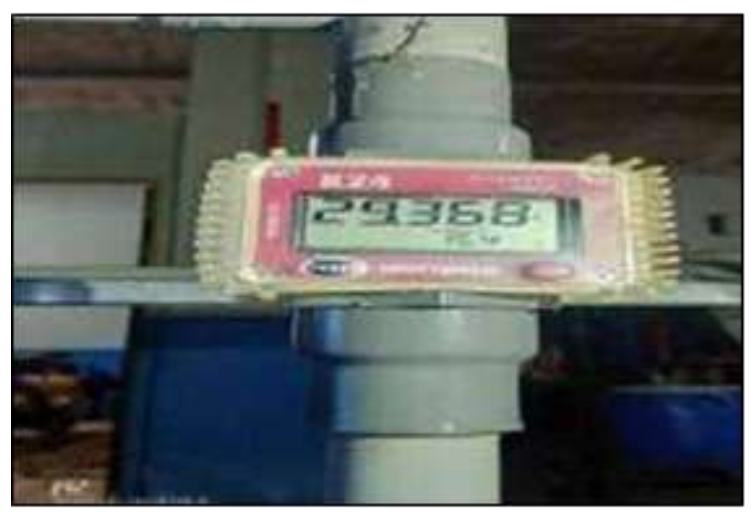

Gambar 5. Pemasangan Turbine Flow meter

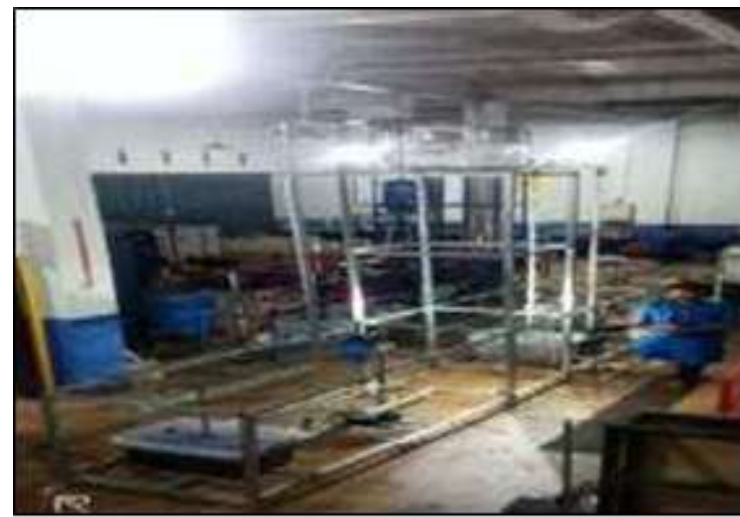

Gambar 6.Hasil rancangan lengkap

Dari hasil pengujian alat yang sudah dirancang didapatkan bahwa debit aliran minyak solar yang dipompakan atau ditransfer melalui pompa 1, pompa 2 dan pompa 3 ke masing - masing Reservoir (Reservoir 2, Reservoir 3, Reservoir 4 \& Reservoir 5) untuk memenuhi proses dari

Sistem Jaringan Perpipaan Transfer Minyak Solar Skala Laboratorium secara kalkulasi telah memenuhi standar dari spesifikasi Pompa Cairan Kental FIRMAN FDP-20 Pompa Solar dan Oli yang 
memiliki kapasitas maksimum sebesar 53 LPM $\left(0,0009 \mathrm{~m}^{3} / \mathrm{s}\right)$. Debit aliran minyak solar rata - rata per data uji untuk Turbine Flowmeter 1 Pompa 1 (Qrata-rata,FM1 P1) dengan waktu sirkulasi (t) 10 menit sebesar $0.0023 \mathrm{~m}^{3} / \mathrm{s}$, untuk Turbine Flowmeter 2

Pompa 2 (Qrata-rata, FM2 P2)sebesar $0.0054 \mathrm{~m}^{3} / \mathrm{s}$, untuk Turbine Flowmeter 3 Pompa 3 (Qrata-rata,FM3 P3) sebesar 0,0053 $\mathrm{m}^{3} / \mathrm{s}$ dan untuk Turbine Flowmeter 4 Pompa 3 (Qrata- rata,FM4 P3) sebesar 0,0050 $\mathrm{m}^{3} / \mathrm{s}$. Jadi dalam waktu sirkulasi $(\mathrm{t})$ per menit untuk masing- masing debit aliran minyak solar rata - rata di bawah kapasitas maksimal dari spesifikasi Pompa Cairan Kental FIRMAN FDP-20 Pompa Solar dan Oli, yaitu:

a. Untuk Debit Aliran Minyak Solar rata - rata Turbine Flowmeter 1 Pompa 1 $($ Qrata-rata,FM1 P1 $)=13,6073 \quad \mathrm{LPM}=$ $0,0002 \mathrm{~m}^{3} / \mathrm{s}$

b. Untuk Debit Aliran Minyak Solar rata - rata Turbine Flowmeter 2 Pompa 2 $\left(\mathrm{Q}_{\text {rata-rata,FM2 }} \mathrm{P} 2\right)=32.4488 \mathrm{LPM}=$ $0,0005 \mathrm{~m}^{3} / \mathrm{s}$

c. Untuk Debit Aliran Minyak Solar rata - rata Turbine Flowmeter 3 Pompa 3 $\left(\mathrm{Q}_{\text {rata-rata,FM3 }} \mathrm{P} 3\right)=32,0058 \mathrm{LPM}=$ $0,0005 \mathrm{~m}^{3} / \mathrm{s}$

d. Untuk Debit Aliran Minyak Solar rata - rata Turbine Flowmeter 4 Pompa 3 $($ Qrata-rata,FM4 P3 $)=30,2062 \mathrm{LPM}=$ $0,0005 \mathrm{~m}^{3} / \mathrm{s}$

e. Untuk Debit Aliran Minyak Solar rata - rata dengan Manual Metode Tampung pada Pompa 2 (Qrata- rata,MT1 R3) $=15,2697 \mathrm{LPM}=0,0003 \mathrm{~m}^{3} / \mathrm{s}$

Dari hasil kalkulasi untuk kecepatan pompa 1, pompa 2 dan pompa 3 yang diijinkan berdasarkan jenis pipa PVC Type AW Schedule Standart 40 (Standar JIS \& ISO 9001 : 2000) berdiameter 3/4". Kecepatan aliran minyak solar yang sesuai dengan spesifikasi Pompa Cairan Kental FIRMAN FDP-20 Pompa Solar dan Oli dengan kapasistas aliran maksimal 53 LPM adalah $3,1007 \mathrm{~m} / \mathrm{s}$

Kerugian tinggi tekan (Head Loss Mayor) rata - rata terbesar yang terjadi di sistem jaringan perpipaan transfer minyak solar skala laboratorium dari Reservoir 2 ke Reservoir 3 pada Turbine Flowmeter 2 dan Pompa 2 (HLMayor,rata-rata,FM2 P2) dengan panjang pipa $6,489 \mathrm{~m}$ sebesar $128,8906 \mathrm{~m}$. Hal ini diakibatkan oleh factor gesekan dalam pipa (gesekan fluida pada dinding pipa dalam) dengan pengaruh panjang pipa, kecepatan, viskositas minyak solar dan khususnya pengaruh system aliran minyak solar yang ditransfer dari menara (Reservoir 2) ke Reservoir 3 (posisi dari atas ke bawah) yang dipaksa menggunakan Pompa 2. Sedangkan kerugian tinggi tekan (Head Loss Mayor) rata - rata terkecil yang terjadi di sistem jaringan perpipaan transfer minyak solar skala laboratorium dari Reservoir 1 ke Reservoir 2 pada Turbine Flowmeter 1 dan Pompa 1 (HLMayor,ratarata,FM1 P1) dengan panjang pipa $6,110 \mathrm{~m}$ sebesar 25,5283 $\mathrm{m}$ walaupun dalam hal ini sama-sama diakibatkan oleh faktor gesekan dalam pipa (gesekan fluida pada dinding pipa dalam) dengan pengaruh panjang pipa, kecepatan, viskositas minyak solar akan tetapi system aliran minyak solar yang ditransfer dari Reservoir 1 menuju menara (Reservoir 2) dengan sistem paksa Pompa 1 (dari bawah ke atas) juga mempengaruhi termasuk ketinggian / elevasi, sehingga laju aliran / kecepatan aliran juga terpengaruh (lebih kecil).

Untuk perbandingan kerugian tinggi tekan (Head Loss Mayor) rata - rata yang terjadi di sistem jaringan perpipaan minyak solar dari Reservoir 2 ke Reservoir 3 antara sistem paksa pada Pompa 2 dengan panjang pipa $6,489 \mathrm{~m}$ dan sistem gravitasi dengan panjang pipa 3,005 memiliki selisih yaitu $108,2681 \mathrm{~m}$. Jadi secara system gravitasi kerugian tinggi tekan (Head Loss Mayor) lebih kecil dibandingkan dengan menggunakan sistem paksa (Pompa 2). Rata - rata pola aliran yang terjadi pada sistem jaringan perpipaan transfer minyak solar skala laboratorium ini adalah Turbulen di masing-masing data pengujian dengan variasi Bukaan Valve $25^{0}\left(\mathrm{BV} 25^{0}\right.$ ),

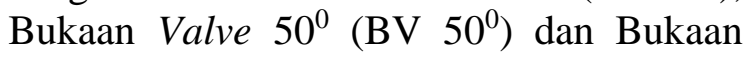
Valve Full (BV Full). Dan hanya 1 (satu) pola aliran Laminar yang terjadi pada 
sistem jaringan perpipaan transfer minyak solar skala laboratorium ini, yaitu di saat transfer minyak solar dari Reservoir 2 ke Reservoir 3 dengan sistem gravitasi sepanjang pipa $3.005 \mathrm{~m}$ pada Data Uji 1 Bukaan Valve $25^{\circ}$ (DU 1 - BV 250).

\section{Kesimpulan}

Dari penelitian ini dapat diambil kesimpulan bahwa media pembelajaran transfer minyak solar dengan menggunakan pompa sentrifugal sudah selesai dibuat dan $100 \%$ bisa bekerja. Alat ini sudah bisa digunakan untuk praktikum pengujian unjuk kerja pompa ditinjau dari segi kecepatan, debit, head loss dan jenis alirannya. Media ini dapat digunakan sebagai media pemebelajaran dan praktikum mahasiswa Program Studi Teknik Mesin Fakultas Teknik dan Ilmu Komputer Universitas Muhammadiyah Pontianak serta bisa digunakan sebagai alat demonstrasi dosen untuk mempermudah dalam menjelaskan mata kuliah pompa.

\section{Ucapan terimakasih}

Ucapan terimakasih penulis tujukan kepada LPPM Universitas Muhammadiyah Pontianak yang telah memberikan dana penelitian sejak perencanaan hingga selesai. Ucapan terimakasih juga kepada rekan-rekan yang telah mendukung dan membantu penelitian ini.

\section{Referensi}

[1] P. Dr, "Sugiyono, Metode Penelitian Kuantitatif Kualitatif dan R\&D." CV. Alfabeta, Bandung, 2008.

[2] Y. Munadi, "Media Pembelajaran Sebuah Pendekatan Baru. Jakarta: Cet. I." GP Press Group, 2013.

[3] T. Firdaus, "Pemanfaatan Media Berbasis Teknologi dalam Pembelajaran," 2018, doi: 10.31219/osf.io/46ckj.

[4] Sularso, "Pompa dan Kompresor," $J$. Chem. Inf. Model., vol. 53, no. 9, pp. 1689-1699, 2004.
[5] I. J. Karassik, J. P. Messina, and W. H. Fraser, Pump_Handbook_IgorKarassik. 2001.

[6] O. Linton, "All you need to know," Acad. Radiol., vol. 15, no. 10, p. 1340, 2008, doi: 10.1016/j.acra.2008.05.013.

[7] A. Muliawan and A. Yani, "Analisa Head Mayor Dan Minor Pompa Chiller Dengan Bukaan Katup Instalasi Pompa Tunggal," JST (Jurnal Sains Ter., vol. 4, no. 1, pp. 63-69, 2018, doi: 10.32487/jst.v4i1.454.

[8] Z. Zainudin, I. M. Adi Sayoga, and M. Nuarsa, "Analisa Pengaruh Variasi Sudut Sambungan Belokan Terhadap Head Losses Aliran Pipa," Din. Tek. Mesin, vol. 2, no. 2, pp. 75-83, 2012, doi: 10.29303/d.v2i2.97.

[9] T. Sujadi, "Fenomena dasar mesin," 2016, [Online]. Available: https://temonsoejadi.id/2014/04/04/d efleksi-fenomena-dasar-mesin/.

[10] E. Eswanto and D. Syahputra, "Analisa Distribusi Kapasitas Aliran Fluida Di Daerah Percabangan Pada Sistem Perpipaan," JTT (Jurnal Teknol. Ter., vol. 3, no. 1, pp. 7-11, 2017, doi: 10.31884/jtt.v3i1.7.

[11] D. Darmanto, “Analisa Kerugian Pemipaan Pada Sambungan Divergen Dan Konvergen," $J$. Momentum UNWAHAS, vol. 1, no. 2, p. 138529, 2005. 